\title{
ALINHAMENTO ENTRE SISTEMAS DE PRODUÇÃO, CUSTO E INDICADORES DE DESEMPENHO: UM ESTUDO DE CASO
}

\section{ALIGNMENT BETWEEN PRODUCTION, COST AND PERFORMANCE METRICS SYSTEM: A CASE STUDY}

\author{
Prof. Sergio Luiz Vaz Dias, D. Sc. \\ Professor - Universidade do Vale do Rio dos Sinos - UNISINOS \\ Graduação e Extensão em Engenharia de Produção \\ Av. Unisinos, 950 - Bairro Cristo Rei - São Leopoldo/RS - Brasil - CEP: 93.022-000 \\ (51)9966-0541 - slvdias@unisinos.br \\ Prof. Heitor Mansur Caulliraux, D. Sc. \\ Professor - Universidade Federal do Rio de Janeiro - COPPE/UFRJ \\ Programa de Pós-Graduação em Engenharia (Pesquisa Operacional e Gerência de Produção) \\ Cidade Universitária, Centro de Tecnologia, Bloco D - Ilha do Fundão. \\ Rio de Janeiro/RJ - Brasil - CEP: 21.945-972 \\ (21) 2562-7415 - heitor@gpi.ufrj.br \\ Prof. José Antônio Valle Antunes Jr., D. Sc. \\ Professor - Universidade do Vale do Rio dos Sinos - UNISINOS \\ Programa de Pós-Graduação em Administração \\ Programa de Pós-Graduação em Engenharia de Produção e Sistemas \\ Av. Unisinos, 950 - Bairro Cristo Rei - São Leopoldo/RS - Brasil - CEP: 93.022-000 \\ (51) 8124-8318-junico@ produttare.com.br \\ Daniel Pacheco Lacerda, M. Sc. \\ Doutorando Universidade Federal do Rio de Janeiro - COPPE/UFRJ \\ Programa de Pós-Graduação em Engenharia (Pesquisa Operacional e Gerência de Produção) \\ Cidade Universitária, Centro de Tecnologia, Bloco D - Ilha do Fundão. \\ Rio de Janeiro/RJ - Brasil - CEP: 21.945-972 \\ (21) 2562-7415 - daniel.lacerda@ gpi.ufrj.br
}

\section{RESUMO}

As evoluções dos sistemas produtivos, em geral, implicam em uma revisão dos sistemas de indicadores e de custos da organização. Isso decorre da necessidade de averiguar corretamente as ações locais no desempenho da empresa em termos operacionais ou econômicofinanceiros. De acordo com a literatura, o alinhamento entre os sistemas de produção, de custeio e de indicadores de desempenho é um pressuposto para o melhor desempenho da empresa. Este trabalho é um estudo de caso de caráter exploratório da trajetória de alinhamento dos sistemas de produção, de custeio e de indicadores de desempenho.

Foram realizadas entrevistas em profundidade, reunidos documentos internos da empresa e consultadas a fontes secundárias. Foi feita a descrição das etapas de implantação dos sistemas de produção e foram registrados os incidentes críticos da empresa, momentos em que ocorreram inconsistências entre os sistemas de produção, de custeio e de indicadores de desempenho. Os resultados evidenciaram que o alinhamento depende de ajustes $\mathrm{e}$ modificações realizados ao longo da trajetória de alinhamento dos sistemas, conferindo um caráter dinâmico do alinhamento entre os sistemas de produção, de custeio e de indicadores de desempenho, e revelando a importância do processo de aprendizado. 
Palavras-Chave: Custos, Indicadores, Produção, Aprendizado, Trajetória.

\begin{abstract}
The evolutions of the productive systems, in general, imply in a revision of the performance metrics systems and costs systems of the organization. This elapses of the necessity to correctly inquire the local actions in the performance of the company in operational or economic-financial terms. In accordance with literature, the alignment enters the expenditure, production systems and of performance pointers one estimated for optimum performance of the company is. This paper is an exploratory case study about the alignment between production system, cost system and performance indicators. In-depth interviews were carried out, confidential documents from companies were gathered and secondary sources were used. A description of production systems implementation stages was given and the critical incidents in the companies were recorded. Critical incidents were interpreted as those moments where inconsistencies between production systems, cost system and performance indicators happened. The results showed that the alignment is based on adjustments and changes along the systems alignment path. This provides a dynamic trait to alignment between production system, cost system and performance indicators as well as shows the importance of a learning process inside the companies studied.
\end{abstract}

Key-words: Costs, Performance Metrics, Production, Organizacional Learnig, Trajectory

\title{
1. Introdução
}

A exigência do mercado globalizado impõe às empresas manufatureiras brasileiras a necessidade de evolução em seus sistemas de produção, indicadores de desempenho e de custos. A evolução dos sistemas produtivos busca maximizar a utilização dos recursos disponíveis e os retornos (econômico-financeiros) em relação aos investimentos realizados. Para avaliar a efetividade das ações realizadas, e se essas ações estão alinhadas com a estratégia da organização, é necessário ter um sistema de indicadores (conjunto de métricas).

Esse sistema de indicadores de desempenho deve demonstrar os impactos das ações organizacionais na melhoria dos processos e nos resultados (financeiros e não financeiros) (FROST, 1999).

Marccelli (2000) salienta que mais ou menos na mesma época, uma série de modernas técnicas de produção e iniciativas gerenciais - movimento pela qualidade, Sistema Toyota de Produção (STP), Teoria das Restrições (TOC), Reengenharia, Gerenciamento do Processo, etc. - postulavam que certos indicadores não financeiros, quando utilizados de maneira sistêmica, poderiam conduzir às mudanças necessárias ao fortalecimento da competitividade dos negócios.

Por sua vez, o sistema de custos tem papéis fiscais e gerenciais na organização. O papel fiscal refere-se a impostos, avaliação de estoques e outras informações que são fornecidas para acionistas, órgãos públicos etc. O papel gerencial do sistema de custos procura fornecer um conjunto de informações aos gestores. As informações fornecidas pelo sistema de custos, vão 
desde o efetivo custo dos produtos, bases para a precificação, avaliação do desempenho das unidades organizacionais em termos financeiros etc. Assim o sistema de custos deve refletir em termos econômico-financeiros as ações locais no desempenho geral da organização.

Lastres (1998) e Muller (1996) postulam que o novo paradigma produtivo inaugurou uma nova dinâmica tecnológica e econômica internacional, com a substituição paulatina de tecnologias intensivas de produção estandardizadas e de massa, características do ciclo de desenvolvimento anterior, por tecnologias intensivas em informação. Desta forma, um tópico relevante consiste na necessidade do alinhamento entre os sistemas de produção, o sistema de custeio e o sistema de indicadores de desempenho da empresa. A necessidade de alinhamento é corroborada (analogamente) por Milgron \& Roberts (1995) em pesquisa que apresenta a sinergia entre estratégia e estrutura em correlação com os resultados obtidos.

Nesse contexto, o objetivo desse trabalho consiste em analisar a trajetória histórica de alinhamento entre os Sistemas Híbrido de Produção (JIC, TOC e STP), o sistema de custeio e o sistema de indicadores de desempenho. Para o atendimento do objetivo do trabalho, analisou-se uma empresa do setor metal-mecânico localizada na região da Serra Gaúcha.

Inicialmente o artigo tratará do referencial teórico que suporta o desenvolvimento do trabalho. Posteriormente, é apresentado o método, onde se descrevem os procedimentos de pesquisa utilizados. Na seqüência, é realizada a descrição do caso, seus resultados e uma análise crítica do mesmo. E finalmente, são apresentadas as principais conclusões do estudo realizado.

\section{Referencial Teórico}

Partindo de uma abordagem ampla, pode-se afirmar que uma estratégia bem definida viabiliza a empresa desenvolver um conjunto de habilidades e competências que, adequadamente ordenadas e alocadas, ajudam na sua viabilidade e singularidade (MINTZBERG \& QUINN, 2001). Projetar um sistema de produção, custeio ou indicadores de desempenho passa pela definição da forma de disposição e combinação dos recursos financeiros, físicos, humanos e organizacionais de uma empresa (BARNEY \& HESTERLY, 1996). Assim, é relevante discutir a respeito da trajetória de produção e do alinhamento dos sistemas de produção, custeio e indicadores de desempenho, a trajetória do alinhamento e a definição da Estratégia da Produção.

\subsection{Trajetória de Produção e de Alinhamento}

A partir da análise da trajetória da empresa de uma maneira geral e da produção em especial, é possível examinar o alinhamento ou a consistência entre os diferentes sistemas que compõe a Organização. Do ponto de vista conceitual, o alinhamento ou a consistência entre os 
sistemas acontece quando as práticas de funcionamento e/ou as soluções tomadas pela empresa convergem entre si. Parcialmente alinhado ou consistente, significa que as práticas de funcionamento e/ou as soluções tomadas pela empresa convergem parcialmente. Isto é, há o alinhamento (convergência) entre alguns sistemas. Finalmente, desalinhado ou inconsistente, significa que as práticas de funcionamento e/ou as soluções adotadas pela empresa são opostas. Conforme Milgron \& Roberts (1995) sugerem em seu trabalho sobre o alinhamento da estratégia e da estrutura, um alinhamento entre os sistemas de custos, produção e indicadores pode apontar para melhores resultados organizacionais.

O processo de alinhamento nas Empresas tende a ser dependente da trajetória da sua evolução, que apresenta várias possibilidades de combinação. O processo de alinhamento também tende a se desenvolver a partir dos paradigmas em voga. No caso deste artigo, um paradigma de produção. Além disso, ele depende do acúmulo de conhecimento, de diferentes formas de aprendizado, da curva de aprendizado e das estratégias de produção da empresa.

A partir da noção de trajetória, utilizada na economia evolucionária para explicar o desenvolvimento tecnológico, o processo de alinhamento é tratado como uma trajetória. Tal como na trajetória de produção, a trajetória de alinhamento está relacionada com as melhorias incrementais e radicais que acontecem nos sistemas empresariais. Os conceitos de aprendizado e acúmulo de conhecimento são vistos no contexto da trajetória de alinhamento, como o acúmulo de conhecimento (aprender antes de fazer) e o aprendizado da empresa (aprender fazendo) em relação à implantação e gestão dos sistemas de produção, custeio e de indicadores de desempenho que interferem na trajetória de alinhamento.

\subsubsection{Noção de Trajetória}

A trajetória de uma empresa se refere ao conjunto de habilidades e competências que ela desenvolveu para a produção de determinados bens e serviços no decorrer de sua história. Sendo assim, a trajetória de uma empresa é definida por fatores internos e externos que exercem pressão sobre decisões tomadas por seus executivos na busca da solução de problemas. Uma vez selecionada e estabelecida, a trajetória ganha uma dinâmica própria que contribui para definir as direções em que se movem as atividades de solução de problemas (DOSI \& MARENGO, 1994). Tal dinâmica influencia as decisões futuras da empresa. Isto também é reforçado por Ruttan (1997), quando afirma que a dependência de trajetória reside na importância da seqüência específica de eventos históricos no nível micro.

A continuidade de uma trajetória está muito relacionada com a seleção. Tais mecanismos definem a probabilidade de sobrevivência das rotinas e habilidades da empresa. As principais 
variáveis de seleção que operam na empresa são a qualidade dos produtos, os preços em relação à concorrência, as expectativas dos investidores, as relações com os clientes e a base tecnológica em relação à da indústria. As variáveis de seleção também são chamadas de fatores externos que influenciam na trajetória, tais como o custo, a qualidade e a tecnologia disponíveis no mercado (ALDERMAN, 1999). Os mecanismos de seleção permitem explicar o que Ruttan (1997) denomina como forças responsáveis pelas mudanças no ritmo e direção da mudança técnica. Mesmo quando a trajetória inicial é gerada na forma de tecnologia 'empurrada' (technology push), as forças de mercado freqüentemente agem para modificar a trajetória de mudança técnica (RUTTAN, 1997).

\subsubsection{Trajetória de Melhorias}

A importância do aprendizado na noção de trajetória deriva da natureza cumulativa do conhecimento, sendo o aprendizado da empresa dependente de trajetória (DODGSON, 1993). A trajetória de melhoria pode ser definida como uma seqüência coordenada de implantação de iniciativas complementares, buscando sustentar melhorias no desempenho e inovações contínuas de processo e produto (DA SILVEIRA, 2002; DA SILVEIRA, 2005).

A expansão do estoque de conhecimento de uma empresa dentro de um determinado paradigma somente é possível na medida em que a empresa constitui uma trajetória naquele paradigma. Isso é precisamente o caso das estratégias de melhoria incremental na função produção. Para as estratégias de melhoria incremental, o 'aprender fazendo' é mais relevante do que o 'aprender antes de fazer' (HAYES et al, 2005). Com a mudança de paradigma por meio da introdução de conhecimentos radicalmente novos, tende a ocorrer uma mudança na trajetória da empresa. A base de conhecimento da empresa está sujeita a uma tensão entre exploração de novos conhecimentos capazes de gerar novas rotinas e competências e a melhor utilização das rotinas e competências existentes (DOSI \& MARENGO, 1994). Como assevera Crossan (1999), reconhecer e gerenciar a tensão entre exploração e melhor utilização do conhecimento existente é uma exigência central na teoria da aprendizagem organizacional.

$\mathrm{O}$ 'aprender antes de fazer' associado à melhoria por meio de salto estratégico está no plano da exploração de conhecimento. A exploração de conhecimento implica no desenvolvimento de estruturas e regras novas, ocorre em um contexto ambíguo e derivam principalmente de ações nos níveis gerenciais superiores da organização (FIOL \& LYLES, 1985). A exploração de conhecimento está ligada ao aprendizado em que a detecção e correção de erros ocorrem com a mudança de normas, políticas e objetivos subjacentes (DODGSON, 1993; PAIVA, 1999; PAIVA et al, 2001; NOOTEBOOM, 2004). 
O 'aprender fazendo' associado à melhoria incremental implica a melhor utilização do conhecimento existente. O conhecimento institucionalizado é aquele com um determinado grau de consenso ou entendimento partilhado pelos membros da organização (CROSSAN, 1999). Algumas das características da melhor utilização do conhecimento são: a repetição, o controle sobre as tarefas imediatas, as soluções encontradas nas atividades incorporadas nas rotinas e contextos bem entendidos.

O conhecimento tácito, sinteticamente definido como o know-how não-codificado detido pelos membros da organização no desenvolvimento de suas atividades e na busca de soluções de problemas, possui um alto custo para ser adquirido e o seu desenvolvimento é dependente de trajetória (path-dependent). Esta é a razão pela qual este tipo de estratégia privilegia a estabilidade dos membros da organização. Isso contribui para a socialização e permite que se aprenda a trabalhar em conjunto. Isso garante a possibilidade da observação direta, que é uma das condições para a disseminação do conhecimento tácito.

Um conceito-chave para entender a dinâmica das trajetórias de melhoria na produção é o de trade-offs. O trade-off expressa o comprometimento com a priorização de uma alternativa no desenho da produção em detrimento de outra. Entretanto, o conceito tradicional de trade-off tem sido criticado pelo conceito de sand cone model desenvolvido por Lapré e Scudder (2004), que é baseado na acumulação de competência, onde a melhoria em um critério competitivo implicaria na melhoria simultânea de outros. Ainda dentro desse tema, Slack (1997) e Teixeira (2005) apresentam a importância dos clientes para os possíveis trade-offs.

No intuito de compreender melhor os tipos de estratégia de melhoria, Hayes et al (2005) criaram um modelo de natureza das atividades de melhoria, apresentado no Quadro 1. Os quadrantes I e IV se referem ao 'aprender fazendo'.

Quadro 1 - Natureza das atividades de melhorias

\begin{tabular}{|c|c|c|}
\hline $\begin{array}{l}\text { Natureza da base } \\
\text { do conhecimento }\end{array}$ & $\begin{array}{l}\text { Melhoria Incremental/infra- } \\
\text { estrutura }\end{array}$ & Melhoria radical / estrutural \\
\hline \multirow[b]{2}{*}{$\begin{array}{l}\text { Tácito: Aprender } \\
\text { fazendo }\end{array}$} & (I) & (IV) \\
\hline & $\begin{array}{l}\text { - Aprendizagem individual } \\
\text { - Melhoria dentro do grupo (ex: } \\
\text { kaizen, PDCA, TQM, JIT) }\end{array}$ & $\begin{array}{l}\text { - Sistema Toyota de Produção; } \\
\text { - Objetivos de longo prazo (ex: melhorias seis } \\
\text { sigma) }\end{array}$ \\
\hline \multirow[b]{2}{*}{$\begin{array}{l}\text { Explícito: } \\
\text { Aprender antes } \\
\text { de fazer }\end{array}$} & (II) & (III) \\
\hline & $\begin{array}{l}\text { - Melhorias entre grupos } \\
\text { - Melhores } \\
\text { práticas/benchmarking }\end{array}$ & $\begin{array}{l}\text { - Melhorias dentro do grupo } \\
\text { - Reengenharia de processo } \\
\text { - Introdução do sistema ERP } \\
\text { - Práticas de Classe Mundial }\end{array}$ \\
\hline
\end{tabular}

Fonte: Hayes et al (2005).

\subsection{Considerações sobre os Sistemas de Produção}




\subsubsection{Sistema Toyota de Produção}

O objetivo de centralidade do Sistema Toyota de Produção (STP) tem sido aumentar a eficiência da produção pela eliminação consistente, sistemática e completa dos desperdícios (GHINATO; 1996, OHNO, 1997). Segundo Ohno (1997), o principal objetivo do STP consiste em produzir muitos modelos em pequenas quantidades.

$\mathrm{Na}$ visão do STP o processo pode ser entendido como o fluxo de produtos ao longo do tempo e do espaço. Assim, o processo compreende todas as etapas pelas quais as matérias-primas se movimentam até se transformarem em um produto acabado (SHINGO, 1996a; SHINGO 1996b). Para realizar melhorias significativas no processo de produção como um todo, devem-se distinguir os aspectos relacionados aos Processos e às Operações. De um lado, a análise focada nas Operações contribui apenas para a redução dos custos de produção. De outro lado, a análise do Processo possibilita ganhos significativos na eficácia do Sistema, através de uma maior agregação de valor ao produto e eliminação daquelas atividades que aumentam os custos, e geram perdas (ANTUNES, 1998).

A análise da rede de operações e processos tem por objetivo maximizar a produtividade ao mesmo em que procura evidenciar e eliminar as perdas do sistema produtivo. Shingo (1996a) afirma que o objetivo central do STP relaciona-se com a eliminação total das perdas. Ao analisar o Mecanismo da Função Produção sob a ótica de melhorias do processo, Shingo (1996b; 2000) identificou quatro fenômenos que constituem o fluxo do objeto (Função Processo) para a transformação de matérias-primas em produtos (Função Operação):

- Processamento: alterações da forma ou matéria, montagem e desmontagem;

- Inspeção: comparação com um padrão especificado;

- Transporte: mudança de localização;

- Espera: espaço de tempo sem que ocorra alguma mudança.

A partir destes fenômenos da produção, Ohno e Shingo identificaram sete grandes tipos de perdas: i) Perdas por superprodução; ii) Perdas por transporte; iii) Perdas por processamento em si; iv) Perdas por fabricar produtos defeituosos; v) Perdas por espera; vi) Perdas por estoques e; vii) Perdas no movimento.

Uma das idéias combatidas no âmbito do STP é a de que havia necessidade de formação de estoques no processo produtivo (estoque em processo) ou no almoxarifado/expedição (matéria-prima/produto acabado). O desenvolvimento teórico e prático do Just-in-Time comprovou que a existência de estoques na realidade apenas encobre imperfeições, constituindo-se, portanto, desperdício. A eliminação de perdas no processo produtivo passa necessariamente pelo aprimoramento deste através da realização de melhorias contínuas. Em 
outras palavras, pode-se dizer que a eliminação sistemática e contínua das perdas nos Sistemas Produtivos acarreta: i) uma redução dos custos globais da operação e ii) aumento das Receitas através da melhoria da qualidade. A conseqüência é o aumento do desempenho econômico-financeiro das Empresas.

\subsubsection{Teoria das Restrições}

Para Goldratt (1996) a meta de uma empresa é ganhar dinheiro agora e no futuro. E coloca duas condições necessárias ao alcance dessa meta: "satisfazer os empregados, tanto no presente como no futuro" e "satisfazer os clientes, tanto no presente como no futuro".

Uma restrição é qualquer coisa que limite um sistema de atingir uma performance superior de acordo com sua meta (GOLDRATT, 1990). Assim, o desempenho do sistema como um todo é determinado pelas suas restrições. Existem restrições de mercado, de material, de capacidade, logísticas, gerenciais e comportamentais (UMBLE \& SRIKANTH, 1990).

De acordo com Gardiner et al (1994), as empresas que implantaram a abordagem da TOC para a produção deslocaram as restrições para o mercado. Para o processo de aprimoramento contínuo Goldratt (1996) propõe cinco etapas de focalização da Teoria das Restrições: i) identificar a(s) restrição(ões) do sistema; ii) decidir como explorar, da melhor forma, a(s) restrição(ões) do sistema; iii) subordinar qualquer outra coisa à decisão anterior; iv) elevar a capacidade das restrições do sistema; e v) não permitir que a inércia seja a restrição do sistema.

A programação da produção segundo a abordagem da TOC é realizada através da lógica do Tambor-Pulmão-Corda (TPC) e do gerenciamento de pulmões, sincronizando a produção (GOLDRATT \& COX, 1989). Goldratt \& Cox (1989) destacam que podem existir nas fábricas alguns poucos recursos cuja capacidade seja inferior à demanda de mercado. $\mathrm{Na}$ verdade, estes recursos limitarão a capacidade da fábrica, podendo-se afirmar que a esta capacidade torna-se igual à capacidade do(s) recurso(s) com menor capacidade de produção.

Sobre esta questão, Goldratt \& Cox (1989) afirmam que a lógica do TPC reconhece que esta restrição (a menor capacidade) fornecerá o índice de produção da fábrica inteira. Portanto, o(s) recurso(s) com menor capacidade - o(s) gargalo(s) - devem prover o " "ritmo" da produção, ou seja, metaforicamente deve(m) ser considerado(s) o Tambor da fábrica. Uma vez identificado o recurso crítico - o Tambor - os recursos que antecedem o mesmo serão "puxados" com um ritmo igual, ou um pouco superiores, ao ritmo da restrição. Esta representa a programação para trás (backward). Após o(s) gargalo(s), os componentes serão "empurrados" até o final do sistema; representa a programação para frente (forward). 
Estes recursos críticos (Tambores) determinam, em grande parte, o desempenho econômicofinanceiro do sistema como um todo. Assim sendo, o Tambor deve ser protegido quanto aos eventuais problemas que possam ocorrer nas máquinas que o antecedem. Esta proteção será denominada de Pulmão de Tempo (Time Buffer), na medida em que assegurará certo tempo de abastecimento do gargalo, de modo que eventuais problemas observados nas operações que antecedem o gargalo, que não ultrapassem os tempos do Pulmão de Tempo, não afetem os Ganhos do Sistema Produtivo (GOLDRATT \& COX, 1989; GOLDRATT, 1994).

O segundo tipo de pulmão é chamado de Pulmão de Montagem (Assembly Buffer). A existência deste novo pulmão é justificada, visando assegurar que todas as peças que passam pelo gargalo sejam realmente montadas. Logo se faz necessário estabelecer um Pulmão em frente a todas as demais linhas de alimentação das montagens que utilizarão as peças que já passaram pelo gargalo. Um terceiro tipo de pulmão é denominado de Pulmão de Entrega/Mercado (Shipping Buffer). Este Pulmão, colocado após o final do fluxo produtivo, antecedendo o mercado, tem por objetivo possibilitar a entrega dos produtos dentro do prazo estabelecido.

Por último apresenta-se o elemento logístico da TOC, ou seja, a Corda. O objetivo da Corda é sinalizar a necessidade de entrada de materiais para a alimentação do gargalo e dos pulmões que antecedem as linhas de montagem.

\subsubsection{Sistemas Híbridos de Produção (STP e TOC)}

Para Corrêa et al, (2001) sistemas híbridos são sistemas de administração que utilizam elementos teóricos e práticos de mais de que uma lógica básica (e.g., JIT, MRP II ou TOC), trabalhando da forma mais integrada possível.

Entre as possibilidades de composição dos sistemas híbridos, Corrêa et. al., (2001) destacam: i) MRP II + JIT; ii) MRPII + Sistema de Programação com Capacidade Fina; e iii) MRP II + Sistema de Gestão de Projetos. O presente trabalho parte, em função do caso estudado, de um Sistema Híbrido que envolve a utilização dos princípios, métodos e técnicas do STP - cujos pilares básicos são o Just-In-Time e a Autonomação - e da Teoria das Restrições.

Os princípios do STP são utilizados principalmente visando à quantificação da eficiência real dos equipamentos. Neste momento se observa à sinergia existente entre a TOC e o STP, uma vez que se aplicam os conceitos do STP para desenvolver os cálculos de eficiência dos postos de trabalho e os conceitos da TOC para a focalização nos recursos restritivos do sistema produtivo. Através do cálculo da eficiência dos recursos, pode-se ter conhecimento de suas 
reais eficiências e, desta maneira, elaborar planos de ação e soluções para os principais motivos de ineficiência da produção.

\subsection{Considerações sobre os Sistemas de Custos}

A Contabilidade de Custos tradicional surgiu associada a uma situação de mercado comandada pela oferta dos bens e serviços (Oferta Global < Demanda Global). Segundo Scarlett (1996) e Bornia (2002), o primeiro objetivo básico dos Sistemas de Custos tradicionais é encontrar os custos dos produtos para avaliação de estoques, permitindo desse modo, a determinação do resultado da empresa pela contabilidade financeira. Para Tatikonda (1998) a contabilidade de custos permite: i) a formação do preço de venda; ii) a avaliação contínua dos Inventários e; iii) utilizar os custos do ponto de vista do controle de gestão da empresa. São três os princípios de custeio, eles são sinteticamente apresentados no Quadro 2.

Quadro 2 - Resumo dos Sistemas de Custeio

\begin{tabular}{|c|l|}
\hline $\begin{array}{c}\text { Filosofia (Sistema) } \\
\text { Custeio por } \\
\text { Absorção Integral }\end{array}$ & Consideração \\
\hline $\begin{array}{c}\text { Custeio por } \\
\text { Absorção Ideal }\end{array}$ & $\begin{array}{l}\text { Apenas uma parcela considerada normal dos custos fixos correspondente ao nível de } \\
\text { utilização real da capacidade produtiva, deve ser repassado aos produtos e o restante } \\
\text { dos custos fixos serem considerados como Perdas da Empresa. }\end{array}$ \\
\hline $\begin{array}{c}\text { Custeio Variável } \\
\text { ou Direto }\end{array}$ & $\begin{array}{l}\text { Nenhuma parcela dos custos fixos aos produtos considerando-os como custos que } \\
\text { devem ser cobertos pelo somatório das margens de contribuição de cada produto } \\
\text { multiplicada pelas quantidades vendidas }\end{array}$ \\
\hline
\end{tabular}

Fonte: os autores, adaptado de (ANTUNES, 1998).

Para instrumentalizar as filosofias (sistemas de custeio) existem os Métodos de Custeio. Antunes (1998) afirma que os métodos de custos são, na verdade, técnicas que objetivam o repasse ou a alocação dos diversos itens de custo da empresa aos produtos. $\mathrm{O}$ Quadro 3 procura apresentar resumidamente alguns dos principais Métodos de Custeio utilizados.

Quadro 3 - Principais Métodos de Custeio

\begin{tabular}{|c|c|}
\hline Método & Consideração \\
\hline $\begin{array}{c}\text { Custo } \\
\text { Padrão }\end{array}$ & $\begin{array}{l}\text { O objetivo principal é oferecer suporte para o controle de custos da empresa, fornecendo um } \\
\text { padrão de comportamento dos custos. Consiste em: } \\
\text { - Fixar um custo-padrão, que servirá de referência para a análise de custo; } \\
\text { - Determinar o custo realmente incorrido; } \\
\text { - Levantar a variação (desvio) ocorrido entre o padrão e o real; } \\
\text { - Analisar a Variação, auxiliando na procura das causas (motivos) que levaram os desvios; }\end{array}$ \\
\hline $\begin{array}{l}\text { RKW ou } \\
\text { Centros de } \\
\text { Custo }\end{array}$ & $\begin{array}{l}\text { Divisão da organização em centros de custos. Os custos são alocados aos centros por meio de } \\
\text { bases de distribuição e depois repassados aos produtos por unidades de trabalho. Normalmente } \\
\text { os centros são determinados considerando-se o organograma, localização, a responsabilidade e } \\
\text { a homogeneidade. }\end{array}$ \\
\hline $\begin{array}{c}\text { ABC ou } \\
\text { Custeio } \\
\text { Baseado em } \\
\text { Atividades }\end{array}$ & $\begin{array}{l}\text { Pressupõe que as atividades consomem recursos, gerando custos, e que os produtos utilizam } \\
\text { tais atividades, absorvendo seus custos. Assim a ABC consiste em seccionar a empresa em } \\
\text { atividades, calcular o custo de cada atividade, compreender o comportamento destas atividades } \\
\text { e alocar os custos aos produtos de acordo com a utilização das atividades. }\end{array}$ \\
\hline UEP ou & Baseia-se na unificação da produção para simplificar o processo de controle de gestão. Os \\
\hline
\end{tabular}




\begin{tabular}{|c|l|}
$\begin{array}{c}\text { Unidades de } \\
\text { Esforço de } \\
\text { Produção }\end{array}$ & $\begin{array}{l}\text { esforços de produção representam todo o esforço despendido no sentido de transformar } \\
\text { matéria-prima nos produtos acabados da empresa. A maior dificuldade do método consiste em } \\
\text { encontrar as relações entre os diversos produtos da empresa }\end{array}$ \\
\hline
\end{tabular}

Fonte: os autores, adaptado de (ANTUNES, 2002).

\subsection{Considerações sobre Sistemas de Indicadores de Desempenho}

Frost (1999) postula que a maioria das organizações utiliza como indicadores de desempenho, os resultados financeiros e outros poucos não financeiros. Em diferentes níveis departamentais, os gerentes se valem dos orçamentos para definirem os objetivos com a gerência de nível imediatamente superior.

Medida é entendida como um atributo, qualitativo ou quantitativo, usado para verificar ou avaliar algum produto por meio de comparação com um padrão (grandeza de referência). O indicador é o resultado de uma medida ou de mais medidas que tornam possível a compreensão de evolução do que se pretende avaliar a partir dos limites - referências ou metas estabelecidos (MOREIRA, 2002; MEYER, 1994). E, finalmente, o sistema de indicadores é uma maneira sistemática de avaliar as entradas, saídas, transformações e produtividade da empresa. O sistema é composto de critérios de desempenho, padrões e medidas que permitem o planejamento, a programação, o monitoramento e o controle dos recursos a fim de satisfazer as necessidades dos clientes e atingir as metas da Organização (LOCKMAY \& COX, 1994). Para Goldratt (1996), indicadores são os diversos elementos que auxiliam a tomada de decisão local, direcionando os esforços em busca da meta global de uma Organização. Hronec (1994, p. 14) afirma que "as medidas de desempenho são os sinais vitais das organizações. Elas quantificam o modo como as atividades em um processo ou a saída de um processo atingem uma meta específica". Axson (1999) complementa um sistema de indicadores de desempenho para contribuir no aprimoramento de processos.

Segundo Rummler \& Brache (1992, p. 167), "uma organização só pode ser maior do que a soma de suas partes, quando a organização é gerenciada”. E para que a organização tenha gerenciamento eficaz o desempenho deve ser medido, caso contrário ela não está sendo gerenciada. E acrescentam enfatizando que para um gerenciamento eficaz a medição é o central, pois sua ausência influencia o desempenho das organizações e, de maneira significativa, o desempenho humano, afirmando que: a) sem medição, não se podem identificar adequadamente os problemas, nem estabelecer um conjunto de prioridades; b) Sem medição, o gerenciamento é um conjunto de adivinhações desordenadas e; c) sem medição, as pessoas não têm certeza de que seu desempenho é adequado ou não.

Existe uma tendência histórica do uso dos indicadores na forma de controles financeiros. Informações relativas à eficiência do uso de recursos e ao custo dos produtos perderam, em 
parte, sua importância (SRIKANTH, 1993). Melhorias no desempenho exigem grandes mudanças, e isso inclui mudanças nos sistemas de medição e gestão utilizados pelas empresas. Será impossível navegar rumo a um futuro competitivo, tecnológico e centrado nas competências, monitorando e controlando apenas as medidas financeiras do desempenho passado. As medidas financeiras são inadequadas para orientar e avaliar as trajetórias que as empresas da era da informação devem seguir na geração de valor futuro, investindo em cliente, fornecedores, funcionários, processos, tecnologia e inovação (KAPLAN \& NORTON, 1997).

\section{Método Utilizado na Pesquisa}

O método utilizado na pesquisa foi o do Estudo de Caso de caráter exploratório com a utilização de técnicas qualitativas, que objetiva investigar a relação entre os eventos fora dos limites dos estudos do laboratório (YIN, 1994; YIN, 2001). Sampieri et al (1991) e Roesch (1999) afirmam que o estudo de caso permite o estudo em profundidade dentro de seu contexto. Esta é a situação do estudo da trajetória de alinhamento do sistema de produção, do sistema de custo e do sistema de indicadores de desempenho.

Desenvolve-se a pesquisa qualitativa por meio da revisão bibliográfica, num primeiro momento e no estudo de caso na etapa seguinte. No que se refere aos prováveis problemas associados à abordagem qualitativa, cabe ressaltar que durante a realização da pesquisa, deve ser buscado o apoio superior das empresas a serem investigadas. Deve-se também esclarecer aos entrevistados os conceitos envolvidos no estudo, seus propósitos, suas limitações e o tipo de participação esperada dos pesquisados. Essas ações têm por objetivo buscar um maior comprometimento dos mesmos assim como coletar mais facilmente as informações desejadas. Esta pesquisa utilizou as seguintes fontes de evidências genéricas para coleta de dados: i) entrevistas em profundidade; ii) documentos da empresa; iii) teses e artigos técnicos sobre a empresa; e iv) registros em arquivos da empresa. O Quadro 4 procura apresentar as etapas que constituíram a realização da pesquisa.

Quadro 4 - Método de trabalho

\begin{tabular}{|c|l|}
\hline Etapa & \multicolumn{1}{c|}{ Procedimentos adotados } \\
\hline $\mathbf{1}$ & Elaboração da definição do problema. Explicitaram-se também os objetivos da pesquisa. \\
\hline $\mathbf{2}$ & $\begin{array}{l}\text { Construção do referencial teórico necessário para a consecução da pesquisa. Para tanto, foi utilizado o } \\
\text { referencial teórico relacionado com os temas: i) sistemas de produção; ii) sistema de custeio; iii) } \\
\text { sistema de indicadores de desempenho; iv) estratégia de produção; e v) trajetória. }\end{array}$ \\
\hline $\mathbf{3}$ & $\begin{array}{l}\text { Definição do método da pesquisa - o estudo de caso - e elaboração do questionário. A partir da revisão } \\
\text { de literatura foi construído um questionário semi-estruturado para a realização de entrevistas em } \\
\text { profundidade. Para uma primeira validação de conteúdo do roteiro das entrevistas, este foi submetido a } \\
\text { três especialistas para verificar se as perguntas permitiriam respostas consistentes com o construto do } \\
\text { trabalho. } \\
\text { Em outros termos, seguindo o procedimento de validação de conteúdo, as observações dos especialistas }\end{array}$ \\
\hline
\end{tabular}




\begin{tabular}{|c|c|}
\hline & $\begin{array}{l}\text { indicaram se as perguntas referentes às variáveis teóricas eram capazes de medir ou analisar tais } \\
\text { variáveis (KING et al, 1994). No momento seguinte, foi realizado um pré-teste do questionário, já } \\
\text { corrigido a partir de observações dos especialistas, em uma empresa. Após o pré-teste, foram feitos } \\
\text { novos ajustes e novamente foi feita uma validação pelos especialistas antes da redação da versão final. } \\
\text { Tanto a validação de conteúdo como o pré-teste, aperfeiçoou o roteiro de entrevistas. }\end{array}$ \\
\hline 4 & $\begin{array}{l}\text { Seleção da empresa. Para a realização desta definição buscou-se ouvir a opinião de especialistas na área } \\
\text { de Sistema de Produção e Estratégia de Produção. Optou-se pela escolha de uma empresa considerada } \\
\text { eficiente e representativa no segmento metal-mecânico. Antes da análise dos especialistas foi } \\
\text { consultada uma fonte secundária: os indicadores de desempenho utilizados pela Revista Amanhã de } \\
\text { agosto de } 2003 \text {. Com base nessa lista, das } 100 \text { (cem) melhores empresa, procurou-se analisar e } \\
\text { selecionar a empresa dentro dos seguintes critérios: pertencer ao ranking das } 100 \text { maiores empresas, } \\
\text { conforme critério do Valor Ponderado de Grandeza (VPG }) \text { da Revista Amanhã ser uma empresa do } \\
\text { setor metal mecânico; ter processo de manufatura discreto; utilizar o sistema de produção híbrido (JIC, } \\
\text { STP e TOC) e existir facilidade de acesso físico e das informações necessárias para o estudo. }\end{array}$ \\
\hline 5 & 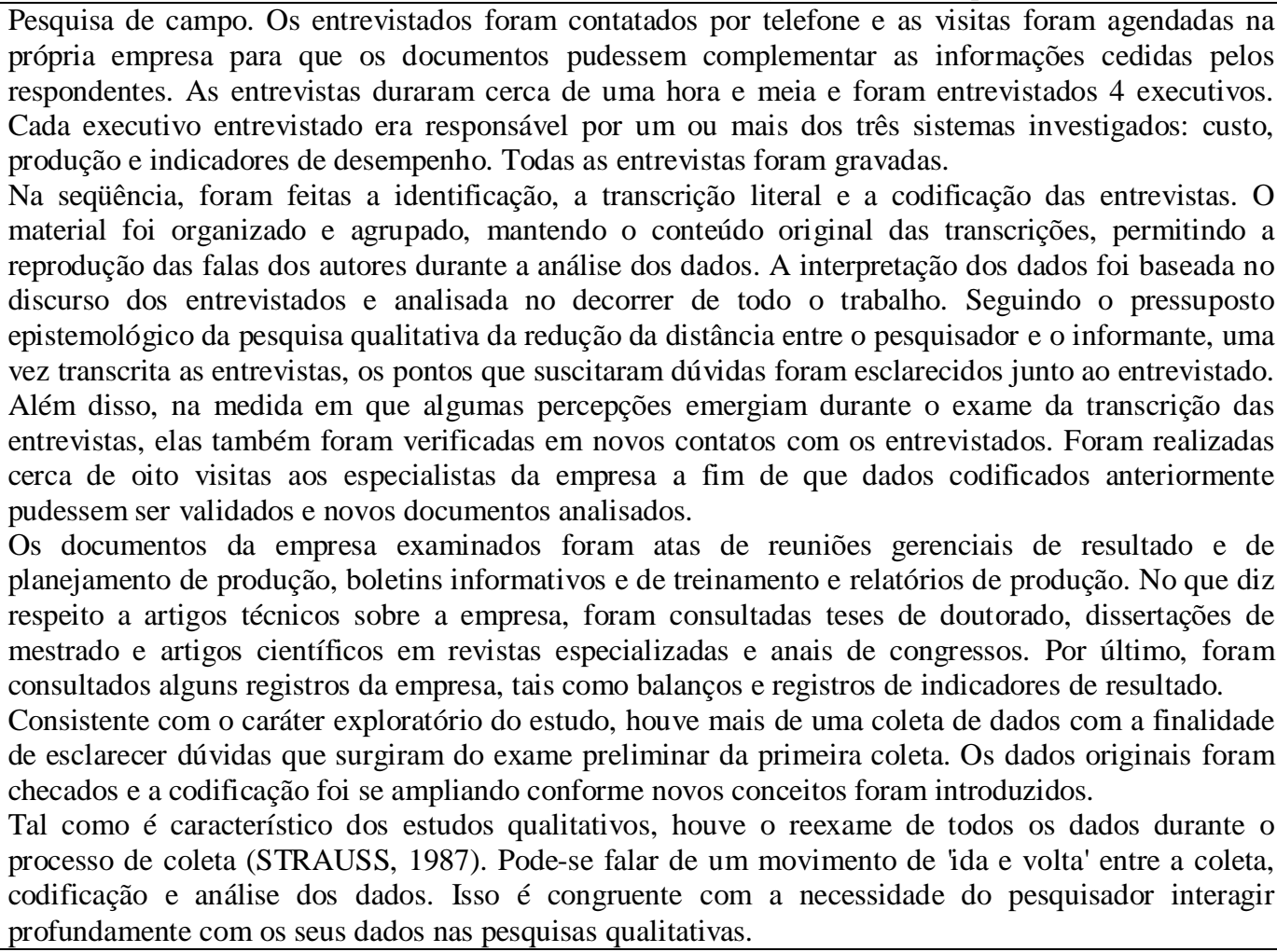 \\
\hline 6 & $\begin{array}{l}\text { Análise individual dos dados da empresa realizada em dois níveis. No primeiro nível, foi feita a análise } \\
\text { do caso individualmente - within-case analysis (YIN, 1994). Na análise do caso, buscou-se entender a } \\
\text { trajetória de alinhamento dos sistemas de produção, de custo e de indicadores de desempenho, as } \\
\text { inconsistências entre os sistemas, os incidentes críticos e como as empresas os superaram. No segundo } \\
\text { nível, tentou-se identificar as possíveis variáveis explicativas para entender a evolução da empresa. } \\
\text { Os dados coletados, exceto das entrevistas e documentos, foram categorizados em dois eixos: um eixo } \\
\text { representando os sistemas analisados e o outro os anos em que ocorreram os eventos. Esta matriz } \\
\text { seguiu o modelo sugerido por Miles \& Huberman (1994) para análise de dados qualitativos. A matriz } \\
\text { foi expandida com a inclusão de novas informações que emergiram durante o movimento de 'ida e } \\
\text { volta' de coleta e codificação dos dados. As necessidades de informações adicionais foram percebidas a } \\
\text { partir da análise de inconsistências das informações coletadas presentes na matriz conceitual. } \\
\text { A linha do tempo permitiu a identificação dos incidentes críticos nas relações entre os sistemas. } \\
\text { Conforme Houaiss (2005), a palavra 'incidente' denota um acontecimento imprevisível que modifica o } \\
\text { desenrolar esperado e normal de uma ação e provoca uma interrupção sentida geralmente como } \\
\text { inconveniente. Tais incidentes foram registrados em uma matriz de trajetória denominada pelo autor de } \\
\text { Matriz da Trajetória Histórica dos Incidentes Críticos. Ela permitiu uma melhor análise dos incidentes. }\end{array}$ \\
\hline
\end{tabular}

Fonte: os autores (2006). 


\section{Estudo de Caso da Empresa X}

As fases foram representadas a partir dos incidentes críticos. Por incidente crítico entende-se um acontecimento imprevisível que modifica o desenrolar esperado e normal de uma ação e provoca uma interrupção sentida geralmente como inconveniente Houaiss (2005). Os incidentes críticos constituem uma interpretação da significância de um evento (TRIPP, 1993). Eles tendem a marcar transformações localizadas no tempo e na vida de uma instituição ou em um fenômeno social. Geralmente, os incidentes críticos não são planejados, antecipados ou controlados.

No caso desse trabalho, os incidentes críticos são os momentos em que se geraram inconsistências nas relações entre o sistema de produção, sistema de custo e o sistema de indicadores de desempenho. Assim utilizará um conceito mais amplo de incidente crítico, isto é, não se considerará as motivações para que o incidente ocorresse (internas ou externas). Utilizar a noção dos incidentes críticos parte da busca do entendimento da trajetória e suas possíveis alterações em função dos impactos do incidente na organização.

As setas da Figura 2 explicitam os incidentes causados pelas implantações ou pelos acontecimentos de eventos específicos. A origem da seta representa o setor onde foi implementado ou onde aconteceu o evento. A outra extremidade identifica o setor que apresentou a inconsistência. A seta contínua e mais espessa revela um incidente crítico em que a inconsistência é suficiente para causar alteração(ões) em outro(s) sistema(s). A seta contínua e, menos espessa, representa um incidente que não é suficiente para causar alteração(ões) em outro(s) sistema(s).

A Figura 1 explicita as etapas da trajetória de alinhamento possíveis entre os sistemas em cada fase. Neste sentido, são adotados modelos teóricos ideais que tenham a capacidade de permitir a análise do caso em cena. Existem inúmeras possibilidades de trajetórias de alinhamentos. 


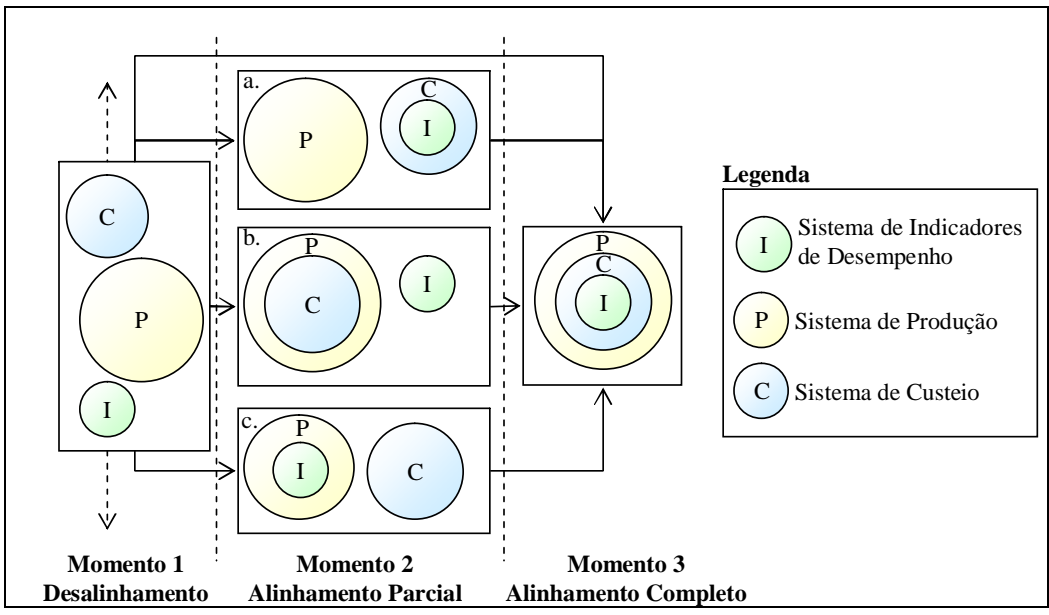

Figura 1 - Exemplos de trajetórias de alinhamento dos Sistemas de: Produção, Custeio e Indicadores de Desempenho. Fonte: Elaborado pelos autores (2006).

Os círculos P, C e I representam, respectivamente, os sistemas de produção $(\mathrm{P})$, custeio (C) indicadores de desempenho (I). Tanto os tamanhos dos círculos C, P e I quanto suas cores não representam diferenças conceituais ou interpretações. São diferentes para viabilizar a circunscrição entre eles, 'explicitar alinhamento' e maior contraste ou facilidade de visualização. A representação visual de um círculo circunscrito em outro, significa que os sistemas estão alinhados.

\subsection{Análise do Caso da Empresa $X$}

Na seqüência está descrita criticamente a evolução histórica do caso da Empresa X, que será chamada desta forma no presente trabalho em função da não autorização, por parte da empresa, da utilização de seu verdadeiro nome. Os marcos das descrições são os incidentes críticos que ocorreram ao longo das diferentes fases observadas conforme a Figura 2.

Em grandes linhas, levando em consideração a noção de incidentes críticos, é possível afirmar que a trajetória da Empresa X pode ser dividida em 3 fases conforme o Quadro 5. Sendo que o horizonte de tempo analisado foi de 1971 a 2004. Por sua vez, o Quadro 6 apresenta os principais eventos ocorridos nos períodos analisados. Os períodos estão destacados através de cores distintas, mas na seqüência das Fases.

Quadro 5 - Linhas de Trajetória da Empresa A

\begin{tabular}{|c|l|}
\hline Fase & \multicolumn{1}{|c|}{ Descrição } \\
\hline Fase 1 & $\begin{array}{l}\text { De 1971 a 1982: O Equilíbrio no alinhamento entre Sistemas de Produção, Sistemas de Custeio e } \\
\text { Sistema de Indicadores de Desempenho no âmbito do Paradigma Just-In-Case. }\end{array}$ \\
\hline Fase 2 & $\begin{array}{l}\text { De 1982 a 2002: Os Movimentos Iniciais no Sentido da Adoção dos Princípios e Técnicas do Sistema } \\
\text { Toyota de Produção e sua ampliação para toda a fábrica. }\end{array}$ \\
\hline Fase 3 & $\begin{array}{l}\text { Período de 2001 a 2004: Mudanças estruturais no Mercado (A Entrada de Novos Concorrentes } \\
\text { Internacionais). }\end{array}$ \\
\hline
\end{tabular}

Fonte: Elaborado pelos autores (2006). 


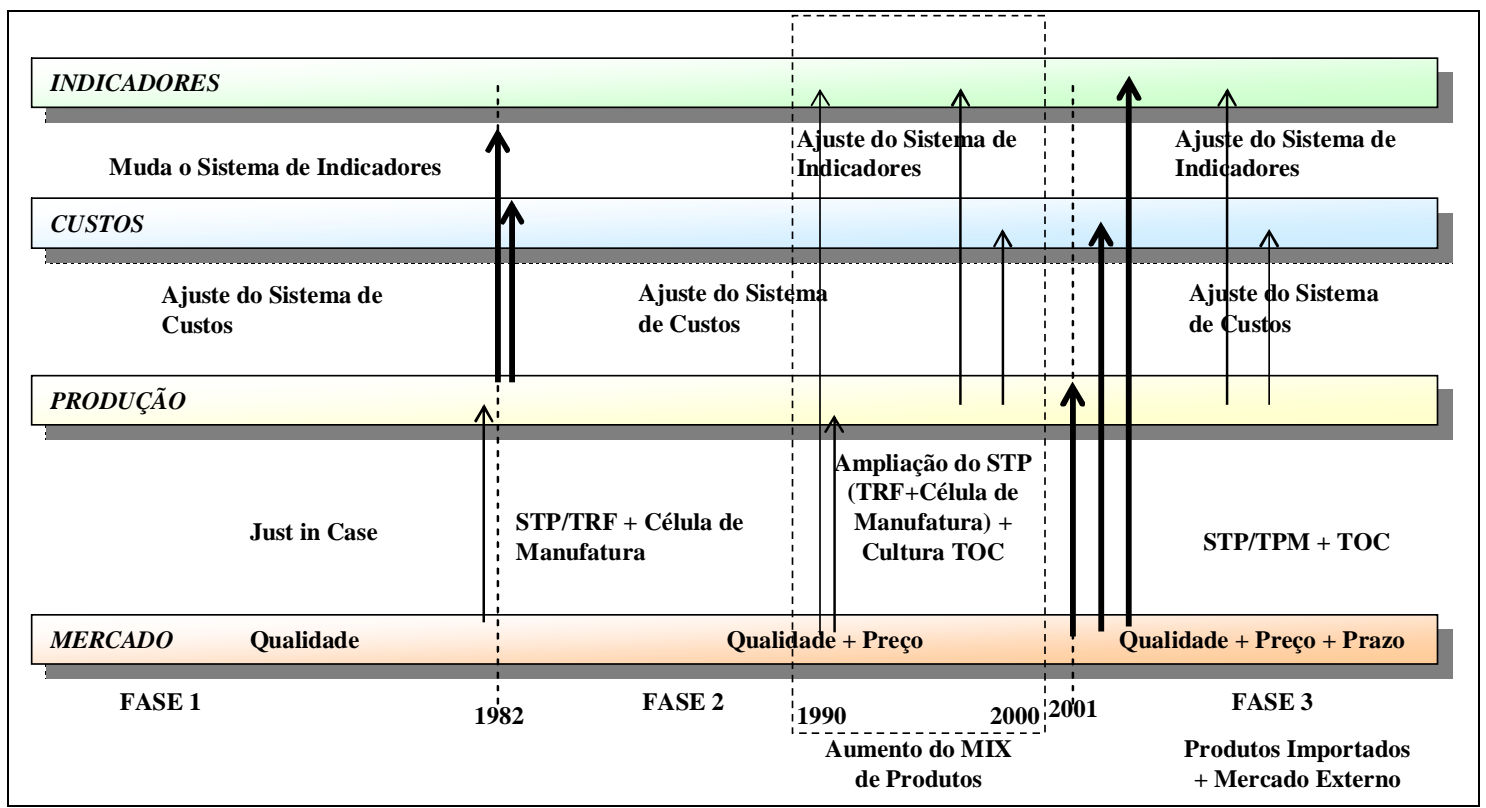

Figura 2 - Trajetória Histórica do alinhamento dos Sistemas de Produção, Custos e Indicadores de Desempenho da empresa X.

Fonte: os autores (2006)

Quadro 6 - Cronologia de fatos das Fases

\begin{tabular}{|c|c|l|}
\hline Fase & Ano & \multicolumn{1}{c|}{ Descrição cronológica } \\
\hline & 1971 & Início de funcionamento com foco estratégico no crescimento contínuo. \\
\cline { 2 - 4 } & 1971 & $\begin{array}{l}\text { Utilização do sistema de custos por absorção integral. Até 1982, o rateio das despesas indiretas } \\
\text { da empresa era feito de maneira única e por toda a fábrica através da utilização do Método da } \\
\text { Unidade Padrão de Produção (UP). É possível postular que havia um alinhamento entre o } \\
\text { Sistema de Produção utilizado - o Just-In-Case - com o princípio e o método de custeio } \\
\text { adotado (princípio do custeio por absorção integral + o método das UP's). }\end{array}$ \\
\cline { 2 - 4 } & 1974 & $\begin{array}{l}\text { Criação do setor de Planejamento e Controle da Produção (PCP). O PCP utilizava o gráfico de } \\
\text { Gantt para identificar qual a máquina que estava freqüentemente com sua capacidade de } \\
\text { produção ultrapassada (gargalo), evidenciando os gargalos da produção. Porém, mostrava o } \\
\text { gargalo através da experiência que o funcionário responsável tinha na fábrica e não pelo } \\
\text { conhecimento dos princípios do TOC (Teoria das Restrições). Tudo era feito de maneira } \\
\text { manual. }\end{array}$ \\
\hline
\end{tabular}

\begin{tabular}{|c|c|l|}
\hline \multirow{2}{*}{2} & 1982 & $\begin{array}{l}\text { Início da implantação das técnicas ligadas à constituição de Células de Manufatura e da Troca } \\
\text { Rápida de Ferramentas em uma área piloto da Empresa. }\end{array}$ \\
\cline { 2 - 3 } & 1992 & $\begin{array}{l}\text { Diretor Presidente e os três diretores proprietários foram ao Japão observar o STP e suas } \\
\text { ferramentas na prática e em empresas similares à Empresa X. }\end{array}$ \\
\cline { 2 - 3 } & 1994 & $\begin{array}{l}\text { Os gerentes da fábrica começaram a visitar as empresas no Japão para observar o que os } \\
\text { diretores falavam nas reuniões gerenciais da empresa. }\end{array}$ \\
\hline & $\begin{array}{l}\text { Mudança da fábrica de talheres para outro prédio o que ocasionou uma mudança do seu leiaute, } \\
\text { ficando, desta forma, com um fluxo parecido com o da fábrica de panelas. Apesar de não ter } \\
\text { linhas tão contínuas como a de panelas, procurou-se fazer uma sincronização da produção, } \\
\text { utilizando-se de esteiras, por causa do número maior de máquinas e da existência de algumas } \\
\text { máquinas mais lentas. Na fábrica de panelas se fazia à produção andar em cima de esteiras, de }\end{array}$ \\
\hline
\end{tabular}




\begin{tabular}{|c|c|l|}
\hline & & $\begin{array}{l}\text { maneira uniforme. Nos talheres era utilizada a noção de lote de transferência, isto é, } \\
\text { transportados lote a lote. Para a empresa, as mudanças das fábricas de panelas e talheres } \\
\text { facilitaram a mudança do sistema produtivo. }\end{array}$ \\
\hline \multirow{3}{*}{3} & 2001 & $\begin{array}{l}\text { O próximo incidente crítico que ocorreu na Empresa foi à entrada de novos concorrentes } \\
\text { internacionais no mercado interno e externo }\end{array}$ \\
\cline { 2 - 3 } & 2002 & $\begin{array}{l}\text { O preço praticado pelo mercado passou a ser fortemente pressionado no sentido de sua redução. } \\
\text { Isto obrigou a empresa à tomada de novas decisões que tendiam a alterar o seu sistema de } \\
\text { custeio. }\end{array}$ \\
\hline
\end{tabular}

Fonte: os autores (2006).

\subsubsection{Fase 1}

Pode-se afirmar que nesse período o crescimento da empresa era sustentado pela totalidade de vendas dos produtos produzidos. Buscava-se a maximização da mecanização do processo produtivo, reduzindo a participação dos custos de pessoal no âmbito do custo total do produto. Em 1971, a Empresa X operava enquanto uma empresa tipicamente Just-In-Case, seguindo assim os pressupostos clássicos do paradigma Taylorista/Fordista. As máquinas eram agrupadas de acordo com os diversos processos similares existentes. O Quadro 6 apresenta a os principais incidentes críticos.

A principal dimensão competitiva da empresa estava relacionada com os aspectos associados à qualidade de seus produtos. Em termos de custos, a empresa tinha um foco prioritário nos controles internos. Nos meses de maio e dezembro, era possível observar um significativo aquecimento da demanda. Isto fazia que nos meses de demanda baixa, a empresa projetasse conscientemente a constituição de estoques, visando atender os meses de demanda aquecida.

No que tange ao Sistema de Indicadores de Desempenho, um dos focos principais encontravase na medição do rendimento da mão-de-obra. Tal medição era feita através da adoção das UP's. A partir do tempo disponível dos funcionários trabalhando na fábrica tornava-se possível calcular quantas UP's poderiam ser teoricamente produzidas. A partir da produção real eram calculadas as UP's realmente produzidas. Baseado nestes dois valores era possível calcular o rendimento ou a produtividade da mão-de-obra.

É essencial perceber que o foco na análise da eficiência/rendimento da mão-de-obra está alinhado com as idéias de controle propugnadas no âmbito do Paradigma da Melhoria das Operações, Just-In-Case.

Neste período, é possível afirmar o sistema de indicadores de desempenho utilizado na empresa envolvia: i) a quantidade total de produção (peças e UP); ii) a medição da capacidade instalada; iii) o cálculo do índice de eficiência de mão-de-obra por funcionário; iv) o consumo de matéria-prima por produto; v) o faturamento e vi) o orçamento de caixa. 
Como resumo da Fase 1, o estudo mostrou que a capacidade instalada da empresa era utilizada plenamente durante a maior parte do ano. Assim, a ociosidade da fábrica tende a zero o que permite afirmar que ocorria uma absorção quase completa dos custos fixos provenientes da compra da capacidade de produção. Finalmente, com a utilização da Unidade Padrão de Produção (UP) como forma de medir o desempenho da empresa (indicador físico e financeiro), o estudo induz à conclusão de que existia um alinhamento entre o sistema de produção utilizado (o Just In Case), o sistema de custo (princípio do custeio por absorção integral + método das UP's) e o sistema de indicadores (capacidade instalada - somatório de todas as máquinas, eficiência de mão-de-obra por funcionário e produtividade em UP's).

\subsubsection{Fase 2}

Conforme se pode observar na Figura 2, o primeiro incidente crítico da trajetória de alinhamento dos sistemas de produção, custo e indicadores de desempenho aconteceu em 1982. Nesse período, foram tomadas as primeiras ações no sentido da implantação do Sistema Toyota de Produção. Aproximadamente em 1990, foram definidos os quatros pilares que os gerentes deveriam perseguir na fábrica: a organização e a limpeza, que estavam ligadas ao programa 5S's da fábrica, a segurança, a qualidade e a produtividade. Para cada um dos pilares foram estabelecidos indicadores. A partir desses indicadores trabalhou-se sua a relação sistêmica com o processo produtivo.

Um exemplo elucidativo das mudanças no Sistema Produtivo está brevemente descrito a seguir. Foi montada uma célula de fabricação envolvendo as operações de estampar, rebarbar e polir. Com isso o fluxo produtivo foi melhorado, incluindo aí a redução dos tempos de atravessamento dos produtos que utilizavam esta célula. As operações em si foram melhoradas, o mesmo ocorrendo com o fluxo como um todo. Do prisma da modelagem do sistema de produção passou-se a considerar as operações da célula como uma só. Desta forma, ficou alterado o cálculo das UP's das peças que passavam nas células de manufatura, bem como o tempo total de mão-de-obra associado à operação.

Os indicadores de desempenho que passaram a ser utilizado quando a empresa passou a adotar o sistema de células de manufatura foram: capacidade instalada da célula, quantidade de peças fabricadas em cada máquina, rendimento da mão-de-obra por setor, índice de retrabalho e refugo e produtividade da fábrica, medida em termos da quantidade total de UP fabricada pelos equipamentos que constituem a célula.

É precisamente esta mudança no Sistema de Produção em direção à lógica do Sistema Toyota de Produção que pode ser caracterizada como o primeiro incidente crítico do prisma do 
Sistema de Gestão Global da Empresa. Isto porque ocorreu uma desestabilização na confiança dos resultados gerados pelo sistema de custos e pelo sistema de indicadores de desempenho. As principais evidências das contradições na obtenção dos resultados estão relacionadas com o fato de que produtos iguais ou semelhantes que passavam no sistema tradicional de produção e nas células de manufatura passaram a apresentar custos consideravelmente diferenciados.

A partir destas constatações a empresa perdeu o seu referencial anterior em termos do custo dos produtos. Como consequiência, do prisma de gestão, a orientação geral passou a ser de que todos os produtos similares passassem a ser manufaturados no mesmo processo de fabricação. O Diretor percebeu que precisava repensar o modo de cálculo utilizado pelo sistema de custo dos produtos que passavam pelas células de manufatura. O principal motivo originou-se pelo fato do sistema de custeio incluir no cálculo o rateio das despesas totais pelo total de horas aplicadas no processo produtivo. Com a introdução das células, as horas aplicadas nas máquinas das células diminuíram, aumentando o custo hora de produção e o custo final.

Os questionamentos também se manifestaram no que tange ao sistema de indicadores. Isto ocorria em função do fato de que, apesar do aumento da quantidade de itens produzidos, o sistema de indicadores de desempenho apontava para uma queda de produtividade na empresa a partir da redução dos indicadores de eficiência das máquinas e da mão-de-obra. A explicação provável era a de que passou a ocorrer uma redução de aproximadamente $20 \%$ da quantidade dos estoques em processos entre as máquinas, que eram contabilizados enquanto itens produzidos, uma vez que passassem nas máquinas que constituíam os roteiros de fabricação dos produtos.

Os fatos apontados brevemente acima fizeram com que houvesse: i) uma perda considerável da confiança em termos da apropriação dos custos dos produtos e ii) um abandono temporário da adoção do sistema de indicadores de desempenho da fábrica. A Direção da empresa concluiu, pela necessidade, que o sistema de custeio e o sistema de indicadores de desempenho precisavam ser repensados e realinhados com a nova proposta de sistema de produção da empresa. A adoção das técnicas do STP, particularmente as células de manufatura e os operadores multifuncionais a elas associadas, seriam mantidas e aprofundadas em termos de implantação. A Empresa claramente optou pela continuação do processo de disseminação dos conceitos e técnicas do Sistema Toyota de Produção por toda a Empresa. 
Os primeiros ajustes e alinhamento foram realizados no sistema de custeio. Posteriormente, o sistema de indicadores de desempenho foi alterado e alinhado aos demais. Esse processo foi favorecido pelo fato do Diretor da empresa ser responsável tanto pelo setor de custos como o da produção. Sendo assim, durante o período de 1991 a 1999 a empresa apresentou o maior salto na implantação das técnicas gerais do Sistema Toyota de Produção, com ênfase na montagem das células de manufatura e na adoção do Método da Troca Rápida de Ferramentas.

Com a expansão da implementação do Sistema Toyota de Produção para toda a empresa, verificou-se uma ampliação nos aspectos que determinaram à desestabilização do sistema de custo e dos sistemas de indicadores de desempenho mencionados anteriormente. A implementação das linhas de montagens e das células de manufatura por produto ou família de produtos por toda empresa levou o sistema de indicadores de desempenho a alterar o indicador de eficiência de mão-de-obra por funcionário e a eficiência de máquina para eficiência por setor.

Com relação à desestabilização do sistema de custo, a empresa decidiu ajustar o preço de produto pelo mercado e mudar a base de rateio das despesas da fábrica. A utilização dos operadores multifuncionais nas células de manufatura estava alterando o total de horas aplicadas de seus produtos. O sistema de custeio continuava penalizando os produtos com menos investimentos em máquinas e ferramentas, pois o rateio desses investimentos continuava sendo feito por toda a fábrica. Para exemplificar, pode-se citar o lançamento de uma nova linha de produto, que necessitava de um alto investimento de ferramentas. A despesa total relativa a esse investimento foi rateada por toda a fábrica aumentando o custo hora de produção e com isso o custo de todos os produtos, inclusive os que não tinham nenhum relacionamento com os investimentos realizados. $\mathrm{O}$ avanço da implementação das linhas de montagem e células de manufatura por produtos ou famílias de produtos facilitava a visualização das inconsistências relacionadas aos rateios realizados.

Como síntese da Fase II do estudo de caso, verifica-se que os primeiros movimentos no sentido da adoção dos princípios e técnicas do Sistema Toyota de Produção caracterizaram o primeiro incidente crítico da trajetória de alinhamento dos sistemas de produção, custo e indicadores de desempenho. Pode ser observado que essa adoção desestabilizou o sistema de custo e o sistema de indicadores de desempenho. Em um segundo momento, e de maneira mais atenuada, o mercado desestabilizou o sistema de produção e o sistema de indicadores de desempenho da empresa. Além disso, a ampliação do STP e das células de manufatura 
também contribuíram para a desestabilização dos sistemas de custo e indicadores de desempenho. A estabilidade somente aconteceu com a ampliação da implementação da TRF (Troca Rápida de Ferramentas) e dos ajustes dos sistemas de custo e indicadores de desempenho.

\subsubsection{Fase 3}

Em 2001 novos concorrentes se inseriram na competição nacional e internacional. No novo ambiente de mercado os clientes deixam de comprar todos os itens de uma família de produtos da mesma empresa e passam a selecionar os itens separadamente provenientes de diversas famílias.

Uma outra mudança importante no mercado consumidor e que acentuou o incidente crítico dessa fase foi a definição do preço do produto como uma nova base de competitividade. A pressão externa tende a induzir a empresa a tomar qualquer decisão, levando em consideração os aspectos relativos ao preço de venda e aos custos envolvidos.

O setor de custo observou que o sistema de custeio fazia o rateio de uma forma única entre o mercado interno e a exportação. Verificou-se que os impostos dos produtos exportados e o dos produtos vendidos no mercado interno eram diferentes. Por essa razão, os produtos exportados não podiam entrar no rateio dos impostos pagos pela empresa. Isso deixava os produtos exportados proporcionalmente mais caros. Considerando o processo de fabricação da empresa, notou-se que alguns produtos, dentro de uma mesma família, estavam sendo beneficiados pelo rateio enquanto outros produtos estavam sendo onerados.

Uma melhor utilização dos ativos de produção através do aumento da quantidade de itens produzidos foi uma das alternativas encontradas pela Empresa X para redução dos custos. A partir dessa possibilidade, a empresa intensificou a utilização da lógica da Teoria das Restrições (TOC) a partir da utilização do Método de Gestão dos Postos de Trabalho gargalos de produção e da utilização da Manutenção Produtiva Total através do combate sistemático das perdas no sistema produtivo.

A empresa ampliou o método de implantação do TPM para reduzir as perdas no posto de trabalho, utilizou o IROG (Índice de Rendimento Operacional Global) como o indicador de gestão do posto de trabalho e os conceitos da TOC na identificação das máquinas gargalos do processo produtivo. Após a execução de cálculos, constatou-se que o IROG da linha de montagem da panela era de $58 \%$. As principais perdas identificadas foram desgastes não uniformes das rodas de polimento, paradas de manutenção mecânica e elétrica do equipamento. Após a solução destes principais problemas, o IROG passou em um primeiro 
momento de $58 \%$ para $66,47 \%$, e em um segundo momento de $66,47 \%$ para $80,6 \%$. A capacidade produtiva da linha desse produto teve um aumento de $38 \%$, o suficiente para atender a demanda por aumento da produtividade.

Pode-se dizer que as mudanças mostradas na Fase 3 foram puxadas pelo mercado através da entrada de produtos importados, vendas para o mercado externo e a dimensão preço como fator competitivo. Esses fatos marcaram o segundo incidente crítico da trajetória de alinhamento dos Sistemas de Produção, Custo e Indicadores de Desempenho. Eles introduziram uma desestabilização nos Sistemas de Custos e Indicadores de Desempenho da empresa.

\section{Conclusões}

Este trabalho teve por objetivo analisar a trajetória de alinhamento dos sistemas de produção, de custeio e dos indicadores de desempenho. Para isso, foi selecionada uma empresa que tivesse passado pela experiência de ter implantado tais sistemas, caracterizando um estudo de caso único. Diversas fontes de dados foram utilizadas, dentre as quais se destacam: entrevistas, relatórios e análise das mais variadas informações.

Embora sem espaço para detalhamento da Fase 1, observou-se que dentro do paradigma Just In Case não houve problema de alinhamento entre os sistemas de produção, de custeio e dos indicadores de desempenho.

Entretanto, as fases 2 e 3 evidenciaram que a introdução de conceitos e técnicas de outros sistemas de produção, como STP ou TOC, geram problemas de alinhamento em relação aos indicadores de desempenho. Foi verificado que a falta do alinhamento entre os sistemas de produção, custos e indicadores de desempenho levam à falta de confiança nas informações. Em casos extremos, pode ocorrer, inclusive, a desistência do uso dessas informações.

Além disso, verificou-se que o aprendizado contínuo com a implantação dos sistemas serviu de base e guia para as futuras ações a serem desenvolvidas. Num processo constante de aperfeiçoamento, as mudanças necessárias para o alinhamento dos sistemas são de natureza estrutural e cultural dentro da organização. Outros trabalhos tornam-se necessários para uma quantificação/correlação entre o ajuste dos sistemas de produção, custos e indicadores de desempenho ao resultado da organização como um todo. Nesses possíveis estudos poderia-se verificar a real influência entre o alinhamento dos sistemas (custos, produção e indicadores) na performance organizacional.

As limitações do trabalho estão ligadas às características metodológicas. O estudo de caso aprofunda o pesquisador acerca de uma problemática, mas limita a generalização dos 
resultados. Logo, novas pesquisas devem ser realizadas para que as observações feitas possam ser validadas ou reavaliadas, contribuindo para a construção do conhecimento científico.

Por fim, é importante destacar as contribuições gerencias do trabalho, pois as empresas que tenham interesse em implantar conceitos de diferentes sistemas de produção devem buscar adaptar seus sistemas de custos e de indicadores de desempenho a fim de evitar a perda de credibilidade dos mesmos. Além disso, tais empresas devem compreender o esforço necessário para adaptar sua estrutura e cultura às alterações possivelmente exigidas em tal empreendimento.

\section{Referências Bibliográficas}

ALDERMAN, N. Innovation in complex capital projects Journal of Economic Geography vol 4, 2004

ANTUNES J. J. A V. Em Direção a Uma Teoria Geral do Processo na Administração da Produção: Uma Discussão sobre a Possibilidade de Unificação da Teoria das Restrições e da Teoria que Sustenta a Construção dos Sistemas de Produção com Estoque Zero. Tese de Doutorado em Administração. Programa de Pós-graduação em Administração da Universidade Federal do Rio Grande do Sul. Porto Alegre, 1998.

AXSON, D. A. J. The Facets Route to Right Answers: Refining approaches for better decision-making through performance reporting. Chicago: Strategy \& Leadership, a publication of Strategic Leadership Forum, pp. 6-10, May - Jun 1999.

BARNEY, J. B; HERSTERLY, W. Organizational Econimics: understanding the relationship between Organizations and Economic Analysis. In: Vários, Handbook of Organizations, Rouledge, London, 1996.

BORNIA, A. C. Análise Gerencial de Custos - Aplicações em Empresas Modernas. Porto Alegre: Editora Bookmann, 2002

CORRÊA, H. L. \& GIANESI, I. G. N. Planejamento Programação e Controle da Produção. 1 ed, São Paulo: Atlas, 2001

CROSSAN, M. M. Organizational learning framework from intuition to institution Academy of Management Review vol. 24, Issue 3 p. 522-537. 1999.

DA SILVEIRA, G. Improvement trajectories in operations and technology management. Technology Analysis and Strategic Management vol. 14, no. 2, 2002

DA SILVEIRA, G. Improving trade-offs in manufacturing International Journal of Production and Economics vol. 95, 27-38, 2005

DODGSON, M. Organizational learning: a review of some literatures Organization Studies vol 13, Issue 3, 1993

DOSI, G. et MARENGO, L. Some elements of an evolutionary theory of organizational competencies in Evolutionary Concepts in Contemporary Economics, ed Richard W. England, Ann Arbor, University of Michigan Press, 1994

FIOL, C. M. \& LYLES, M. A. Organizational Learning Academy of Management Review vol. 10,1985 
FROST, B. Performance Metrics: The New Strategic Discipline. Chicago: Strategy \& Leadership, a publication of Strategic Leadership Forum, pp. 34-35, May-Jun, 1999.

GHINATO, P. Sistema Toyota de Produção - Mais do que simplesmente Just-In-Time. Caxias do Sul: Editora da Universidade de Caxias do Sul, 1996.

GOLDRATT, E. M. \& COX, J. F. A Corrida pela Vantagem Competitiva. São Paulo: Editora Educator, 1989.

GOLDRATT, E. M. \& COX, J. F. A Meta. São Paulo: Editora Educator, 1994.

GOLDRATT, E. M. A Síndrome do Palheiro - Garimpando Informações num Oceano de Dados. São Paulo: Editora Educator, 1996.

GOLDRATT, E. M. Teoria das Restrições. New Haven, CT, Goldratt Satellite Program/ Avraham Y. Godratt Institute do Brasil, 1999.

GOLDRATT, E. M. What Is This Thing Called Theory of Constraints and How It Should Be Implemented? New York : North River Press, 1990.

HAYES, R.; PISANO, G.; UPTON, D et. al. Pursuing The Competitive Edge. Danvers: John Wiley \& Sons, 2005

HOUAISS Dicionário Eletrônico da Língua Portuguesa. www.dicionariohouaiss.com.br, 2005

HRONEC, S. M. Sinais Vitais: usando medidas de desempenho de qualidade, tempo e custo para traçar a rota para o futuro de sua empresa. São Paulo: Makron Books, 1994.

KAPLAN, R. S. \& NORTON, D. P. A Estratégia em Ação: Balanced Scorecard. 3 ed. Rio de Janeiro: Campus, 1997

KING, k. Designing social inquiry: scientific inference in quantitative research. Princenton: Princenton University Press, 1994

LAPRÉ, M. A. \& SCUDDER, G. D. Performance Improvement Paths in the U.S. Airline Industry: Linking Trade-offs to Asset Frontiers. Production and Operations Management Society, 2004

LASTRES, H. “Globalização e Inovação Localizada” Nota Técnica 01/98 - Projeto de pesquisa apoiado pela Diretoria de Políticas Públicas do IPEA (coord.: Cassiolato). (IE/UFRJ, 1998).

MARCCELli, R. P. O Papel dos Indicadores de Desempenho na Estratégia das Organizações para o aprimoramento de Processos: um Estudo de Caso. Dissertação de Mestrado em Engenharia de Produção. Programa de Pós-Graduação em Engenharia de Produção da Universidade Federal de Santa Catarina, 2000.

MEYER, C. How the Right Measures Help Teams Excel. Boston: Harvard Business Review, pp. 94-103, May-Jun. 1994

MILES, Matthew. B. \& HUBERMAN, A. Michael Qualitative data analysis: an Expanded sourcebook. Thousand Oaks: Sage, 1994.

MILGRON, Paul, ROBERTS, John. Complementarities and fit Strategy, structure, and organizational change in manufacturing. Journal of Accounting and Economics, vol. 19, Issue 5, 1995.

MINTZBERG, H. \& QUINN, J. B. O Processo da Estratégia 3 ed. Porto Alegre: Bookmann, 1998 e 2001. 
MOREIRA, E. Proposta de uma sistemática para o alinhamento das ações operacionais aos objetivos estratégicos, em uma gestão orientada por indicadores de desempenho. Tese de doutorado em Engenharia de Produção. Programa de Pós- graduação em Engenharia de Produção da Universidade Federal de Santa Catarina, 2002.

MULler, C. J. A Evolução dos Sistemas de Manufatura e a Necessidade de Mudança nos Sistemas de Controle e Custeio. Dissertação de mestrado em Engenharia de Produção. Programa de Pós-Graduação em Engenharia de Produção da Universidade Federal do Rio Grande do Sul, 1996

NOOTEBOOM, B. Institutions and Forms of Co-ordination in Innovation Systems, 2004.

OHNO, T. Sistema Toyota de Produção - Além da Produção em Larga Escala. Porto Alegre: Bookmann, 1997

PAIVA, E. L. Conhecimento Organizacional e o Processo de Formulação de Estratégias de Produção. Tese de Doutorado em Administração. Programa de Pós-Graduação em Administração da Universidade Federal do Rio Grande do Sul. Porto Alegre, 1999.

PAIVA, E. L.; CARVALHO, J. M.; FENSTERSEIFER, J. E. Estratégia de Produção e de Operações: Conceitos, Melhores Práticas e Visão de Futuro. Porto Alegre: Bookmann, 2004

ROESCH, S. M. A. Projetos de Estágios e de Pesquisa em Administração - Gui para Estágios, Trabalhos de Conclusão, Dissertações e Estudos de Caso. $2^{\text {a }}$ ed. São Paulo: Atlas, 1999

RUMMLER, G. A., BRANCHE, A. P. Melhores desempenhos das empresas: uma abordagem prática para transformar as organizações através da reengenharia. São Paulo: Makron Books, 1994.

RUTTAN, V. W. Induced Innovation, Evolutionary Theory and Path Dependence: Sources of Technical Change. The Economic Journal vol.107, no. 444 p. 1520-1529, 1997

SAMPIERI, R. Metodología de la Investigación. México, McGraw-Hill, 1991.

SCARLETT, B. In Defence of Management Accounting Applications. Management Accounting, pp. 46-47, january, 1996

SHINGO, S. O Sistema Toyota de Produção. Porto Alegre: Bookman, 1996b.

SHINGO, S. Sistema de Troca Rápida de Ferramentas - Uma Revolução nos Sistemas Produtivos. Porto Alegre: Bookmann, 2000.

SHINGO, S. Sistema Toyota de Produção - Do ponto de vista da Engenharia de Produção. Porto Alegre: Editora Bookman, 1996a.

SLACK, N.; CHAMBERS, S.; HARLAND, C. et al. Administração da Produção. São Paulo: Atlas, 1997

SRIKANTH, M. L. \& CAVALlARO Jr, H. E. Regaining Competitiveness. Great Barrington (MA): North River Press, 1993

STRAUSS, A and CORBIN, J. Basics of Qualitative Research: Grounded theory Procedures and Techniques, Sage, Newbury Park, CA., 1990.

TATIKONDA, M. V. Just-In-Time and Modern Manufacturing Environments: Implications for cost Accounting. Production and Inventory. Management Journal, First Quarter, pp. 1-5, 1988 
TEIXEIRA, R. Trade-offs em serviços customizados e o ponto de vista do cliente. Dissertação de Mestrado em Administração. Programa de Pós-graduação em Administração da Universidade do Vale do Rio dos Sinos. São Leopoldo, 2005.

TRIPP, D. Critical incidents in teaching, London, Routledge, 1993

UMBLE, M. M. \& SRIKANTH, M. L. Synchronous Manufacturing. South-Western Cincinnati: Publishing CO., 1990.

YIN, R. K. Case Study Research: Design and Methods. 2.nd. Thousand Oaks: Sage, 1994 $171 \mathrm{p}$.

YIN, R. K. Estudo de Caso: Planejamento e Métodos. 2.nd. Porto Alegre: Bookmann, 2002

${ }^{\text {i }}$ VPG - Valor Ponderado de Grandeza resulta da soma, com pesos específicos, dos três principais componentes do balanço: patrimônio líquido ajustado (50\%), receita bruta (40\%) e resultado - lucro ou prejuízo - líquido (10\%). Patrimônio líquido ajustado é o patrimônio líquido, excluído o resultado líquido do exercício (REVISTA AMANHÃ, 2003).

Artigo recebido em 13/05/2006 e publicado em 21/08/2007. 